\title{
Mars and Earth: a halogen story
}

\author{
LORRAINE RUZIE-HAMILTON ${ }^{1}$, PATRICIA CLAY ${ }^{2}$, \\ BRIAN O'DRISCOLL ${ }^{1}$ AND RAY BURGESS ${ }^{1}$ \\ ${ }^{1}$ University of Manchester \\ ${ }^{2}$ The University of Manchester \\ Presenting Author: lorraine.ruzie@manchester.ac.uk
}

The present day highly volatile element (carbon, nitrogen, halogen, noble gas) distribution between the interiors and exospheres of the telluric planets reflects the integrated history of accretion and interaction between their different reservoirs [1]

Compositional heterogeneities of these elements in their respective mantles are difficult to reconcile with known accretionary or exosphere endmember sources. Conservative tracers such as noble gases have provided a new perspective on the nature and dynamic interplay between the surface reservoirs and the deeper reservoirs [2, 3].

Halogens are similarly conservative but remain relatively underexploited. Information on the bulk halogen composition of martian meteorites is limited, particularly for $\mathrm{Br}$ and I, largely due to the difficulty in measuring ppb-level $\mathrm{Br}$ and $\mathrm{I}$ abundances in small sample sizes [4]. The same is true for the terrestrial samples coming from the most depleted part of the mantle [5].

In this study, we address these challenges by using the neutron irradiation noble gas mass spectrometry (NI-NGMS) method [6] to measure the heavy halogen composition of depleted shergottite meteorites [7] and depleted mid-oceanic ridge basalts. We have complemented these measurements with noble gas isotope determinations on unirradiated aliquots of companion samples.

We will compare the halogen budgets of both planets to understand their similarities and differences and how the integration of geological events has modified their respective budgets over time.

References:

1. Halliday, A. Geochimica et Cosmochimica Acta 105, 146-171 (2013)

2. Holland, G. \& Ballentine, C.J. Nature 441, 186-191 (2006).

3. Ott, U., Swindle, T. D., \& Schwenzer, S. P. (2019). Processes. In J. Filiberto \& S. P. Schwenzer (Eds) (pp. 35-70)

4. Rampe, E. B., Cartwright, J. A., McCubbin, F. M., \& Osterloo, M. M. (2018). In D. E. Harlov \& L. Aranovich (Eds.), (pp. 959-995).

5. Kendrick, M. A., Hémond, C., Kamenetsky, V. S., Danyushevsky, L., Devey, C. W., Rodemann, T., Perfit, M. R. (2017). Nature Geoscience, 10, 222.

6. Ruzié-Hamilton, L., Clay, P. L., Burgess, R., Joachim, B., Ballentine, C. J., \& Turner, G. (2016). Chemical Geology, 437C, 77-87.

7. Clay, P. L., Joy, K. H., O’Driscoll, B., Busemann, H., Ruzié-Hamilton, L., Burgess, R., .Ballentine, C. J. (2020). American Mineralogist, 105(3), 289-306. 